\title{
Effect of hydrodynamics factors on sediment flocculation processes in estuaries
}

\author{
Aisha Mhashhash ${ }^{1} \cdot$ Bettina Bockelmann-Evans ${ }^{1} \cdot$ Shunqi Pan ${ }^{1}$
}

Received: 11 November 2016/Accepted: 17 September 2017 /Published online: 26 December 2017

(C) The Author(s) 2017. This article is an open access publication

\begin{abstract}
Purpose Cohesive sediment is able to flocculate and create flocs, which are larger than individual particles and less dense. The phenomenon of flocculation has an important role in sediment transport processes such as settling, deposition and erosion. In this study, laboratory experiments were performed to investigate the effect of key hydrodynamic parameters such as suspended sediment concentration and salinity on floc size and settling velocity. Results were compared with previous laboratory and field studies at different estuaries.

Materials and methods Experimental tests were conducted in a 1-L glass beaker of 11-cm diameter using suspended sediment samples from the Severn Estuary. A particle image velocimetry system and image processing routine were used to measure the floc size distribution and settling velocity.

Results and discussion The settling velocity was found to range from 0.2 to $1.2 \mathrm{~mm} \mathrm{~s}^{-1}$. Settling velocity changed in the case of increasing suspended sediment concentration and was controlled by the salinity. The faster settling velocity occurred when sediment concentration is higher or the salinity is lower than 2.5. On the other hand, at salinities higher than 20, in addition to increasing SSC, it was found that the situation was reversed, i.e. the lower the sediment concentration, the faster the settling velocity.

Conclusions Sediment flocculation is enhanced with increasing sediment concentration but not with increasing salinity.
\end{abstract}

Responsible editor: Sabine Ulrike Gerbersdorf

Bettina Bockelmann-Evans

Bockelmann-Evans@ cardiff.ac.uk

1 Hydro-environmental Research Centre, School of Engineering, Cardiff University, The Parade, Cardiff CF24 3AA, UK
Keywords Density $\cdot$ Flocculation $\cdot$ Salinity $\cdot$ Settling velocity $\cdot$ Severn estuary $\cdot$ Suspended sediment

\section{Introduction}

Cohesive sediments are regarded as one of the most important features of estuaries around the world. The size of cohesive sediment particles normally ranges from 0.98 to $63 \mu \mathrm{m}$ (Hjulström 1935). Under certain conditions, these sediments come together (flocculate) to form large aggregates, namely flocs, which are larger but less dense than individual particles. This flocculation phenomenon has a strong influence on the sediment transport processes of deposition, erosion and settling (Fennessy et al. 1994). Improving understanding of the significance of flocculation processes is highly desirable because they may exert an impact on the pollutants such as nutrient and heavy metals by which more floc can remove nutrient from the water system (Manning et al. 2013). Moreover, the formation of flocs near the surface decreases the penetration of sunlight through the water column, which constrains the production of plankton. These processes have a direct effect on water quality. The accurate prediction of the settling velocity of cohesive sediment in Severn estuary is required for better understanding of (a) estuarine bathymetry changes, (b) where the deposition and resuspension occur and (c) estuarine contaminant transport processes (Kirby et al. 2008; Kirby 2010).

In general, flocs are classified into two types, namely, microflocs and macroflocs; cohesive sediment flocculates to form small microflocs first, and then macroflocs by combining the microflocs (Eisma 1986; Manning 2001). Microflocs can be classified as those aggregates which do not exceed a spherically equivalent diameter of $100 \mu \mathrm{m}$ and have a settling velocity of less than $1 \mathrm{~mm} \mathrm{~s}^{-1}$ (Lafite 2001). The state of 
microflocs continually changes in response to the hydrodynamic parameters, the physico-chemical and the environmental conditions. These microflocs can develop into larger flocs called macroflocs which behave very differently. Macroflocs have a diameter larger than $100 \mu \mathrm{m}$ and a settling velocity between 1 and $15 \mathrm{~mm} \mathrm{~s}^{-1}$ (Fennessy et al. 1994; Manning and Dyer 1999; Whitehouse et al. 2000; Lafite 2001; Manning 2001; Manning 2004a; Manning and Dyer 2007; Manning et al. 2010b; Manning and Schoellhamer 2013; Manning et al. 2013; Soulsby et al. 2013; Mehta 2014).

The flocculation of fine sediments can occur due to two different mechanisms: one is to bring the particles into direct contact with each other by turbulence; and the other is to stick the flocs together by biological activity and electrostatic charges such as that of organic matter and salinity (Dyer and Manning 1999; Spearman et al. 2011). Biological activity is reflected in the presence of extra-cellular polymeric substances (EPS), the sediment can be more cohesive by sticky EPS secreted by diatoms. The effect of such biological processes in binding sediment particles allows non-cohesive sand particles to flocculate become part of flocs together with cohesive sediment (Manning et al. 2011). In many estuarine water, transported sediment can consist of both mud and sand, which is a direct effect on the flocculation processes (Manning et al. 2010a).

The flocculation process mainly occurs in regions of very low salinity, usually between salinities of 1 and 2.5 (Wollast 1988), and it is affected by hydrodynamical changes which can alter the suspended sediment particle by modifying its effective particle size, shape, porosity, density and composition. The flocculation properties of floc size, settling velocity and density have been identified as the key parameters for modelling of sediment and contaminant transport (Droppo et al. 1997; Cheviet et al. 2002). Numerous studies have been carried out to investigate the flocculation phenomenon in the laboratory, (Serra et al. 1997; Manning and Dyer 1999; Mikes et al. 2004; Maggi 2005). Due to the complexity of the natural system, many simplifications are made in laboratory studies to control the different variable parameters in the flocculation process. In laboratory experiments, one of the main parameters for studying the flocculation process is the turbulent agitator, which is used to create conditions that resemble as closely as possible the natural estuarine environment.

Four different devices, namely the jar test (Mikes et al. 2004), annular flume (Dyer and Manning 1999), sedimentation column and turbulence grid (Maggi 2005), and the Couette device with a video camera system (Serra et al. 1997; Serra and Casamitjana 1998) have been used for generating turbulence and flocculation in the laboratory. A laboratory video analysis method was developed for this study to measure the size of the flocs. This instrumental set-up requires little equipment and is easy to implement in the laboratory. It consists of a glass bowl, CCD camera and variable speed agitator control for the turbulent level inside the bowl. The floc size can then be measured under varying turbulent conditions.

This study aims to determine the effect of increasing suspended sediment concentration (SSC) alongside salinity on the flocculation phenomenon. The SSC has been chosen as the relevant parameter which governs the collision rate and subsequent degree of flocculation of particles in estuarine water. The formation of aggregates at high and low salinities was chosen to simulate the natural processes of the cohesive particles passing from freshwater to high saline water. Floc size and settling velocities were measured during these experiments.

\section{Materials and methods}

\subsection{Overview of study area}

The Severn Estuary, located between South East Wales and South West England, is the largest tidal river in the UK and has the third highest tidal range in the world with a spring tide of up to $14.7 \mathrm{~m}$ (Kadiri et al. 2014). The estuary generates high currents that exceed $3 \mathrm{~m} \mathrm{~s}^{-1}$ (Gao et al. 2011). The river system has a total catchment area of approximately $25,000 \mathrm{~km}^{2}$ (Jonas and Millward 2010), and the estuary has a total channel length of $137 \mathrm{~km}$. The major tributaries of the Severn are the Usk, Wye (on the Welsh side) and the Stour (on the English side). The tidal range varies significantly along the estuary and over time. The average spring and neap tidal ranges are 12.3 and 6 . $5 \mathrm{~m}$, respectively (Kirby 2010). The annual suspended sediment load has been approximated at $1.6 \times 10^{9} \mathrm{~kg} \mathrm{year}^{-1}$; nearly $1.25 \times 10^{9} \mathrm{~kg} \mathrm{year}^{-1}$ of which is discharged from the rivers Wye, Avon and Severn (McLaren et al. 1993). Sediment samples were collected from the Severn Estuary 'Slipway' as shown in Fig. 1. The samples were kept in a cool box and then returned immediately to the laboratory where they were stored in a refrigerator in order to minimise biological activity.

\subsection{Instrumentation}

Flocculation experiments were conducted in a 1-L glass beaker of $11-\mathrm{cm}$ diameter. It was equipped with a variable speed agitator to control turbulence of the flow inside the beaker. A settling column with a diameter of $5 \mathrm{~cm}$ and a height of $40 \mathrm{~cm}$ was used to measure the flocs' settling velocities. Flocs were introduced from the top of the settling column filled with water, where the falling flocs were filmed using a PIV system, as shown in Fig. 2. The PIV system consists of a backlight which is positioned opposite the CCD camera to provide a uniform black background upon which particles appear as white, the CCD camera had 


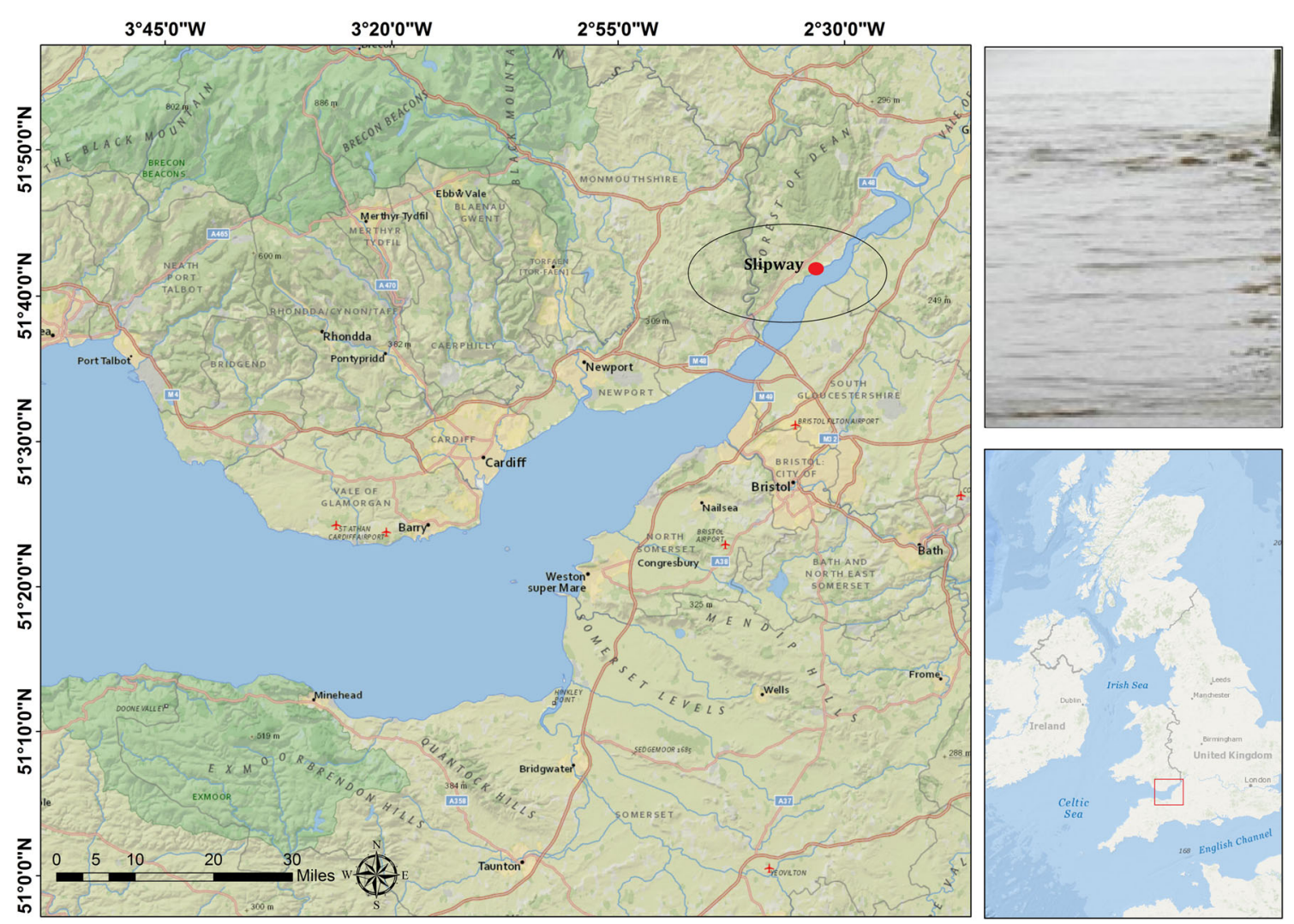

Fig. 1 Map of Severn Estuary showing the location of sampling, slipway $\left(2^{\circ} 30^{\prime} 00.67^{\prime \prime} \mathrm{N}, 51^{\circ} 42^{\prime} 52.12^{\prime \prime} \mathrm{W}\right)$

$1392 \times 1040$ pixel sensitivity, focal length, $f$, of $9 \mathrm{~mm}$ and a maximum frequency of $30 \mathrm{fps}(\Delta \mathrm{t}=1 / 30 \mathrm{~s})$, a Polytec BVS11 Wotan flash stroboscope and trigger box, fibre optic cable and limelight. The PIV system has been validated for measuring settling velocity of artificial sand with three different sizes (63, 150 and $212 \mu \mathrm{m})$, where the settling velocity using PIV camera compared well with the theoretical result using Stoke's law. The PIV system was found to be an appropriate proxy for estimating floc settling velocity. The results show an accuracy of $90 \%$ to estimate the size and settling velocity of the sand

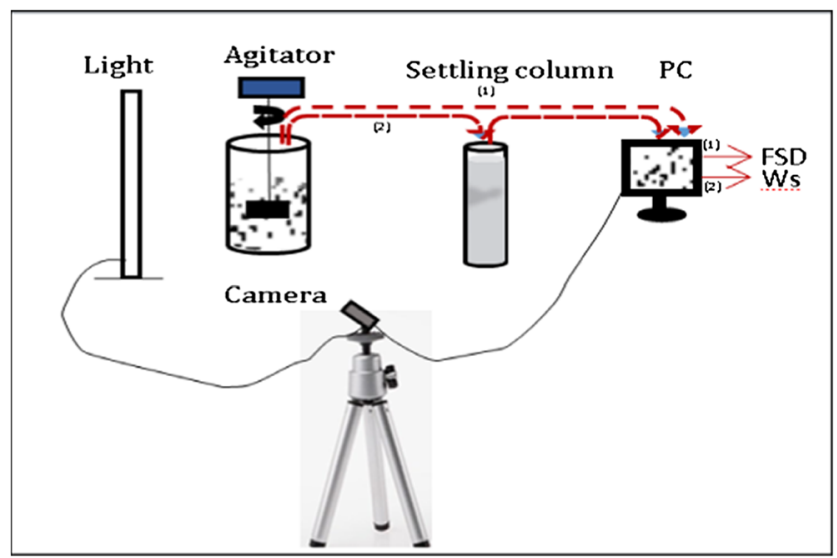

Fig. 2 Schematic diagram of the PIV system, settling column, sample bowl and stirrer samples. Due to the optical limitations, mimicking floc settling behaviour in the laboratory using 1-L glass beaker is operational only for sediment concentrations below $0.35 \mathrm{~g} \mathrm{l}^{-1}$ (Verney et al. 2009). It was found that the main limitation of the PIV experiments carried out in this study was the light source, which was not strong enough to operate with sediment concentration above $0.25 \mathrm{~g} \mathrm{l}^{-1}$.

\subsection{Experimental procedures}

Natural flocculation processes are difficult to reproduce in laboratory experiments due to the complexity of processes involved. Nevertheless, laboratory experiments are valuable because they systematically investigate the effect of specific parameters such as salinity, suspended sediment concentration and turbulence under controlled conditions (Manning 2004b; Manning et al. 2004; Mikes et al. 2004). This study focuses on the influence of suspended sediment concentration (SSC) alongside salinity on the floc size and settling velocity.

The experimental method consists of two main steps. The first step was to apply the highest tested shear stress of $60 \mathrm{~N} \mathrm{~m}^{-2}$ to break down any potential macroflocs in suspension as the initial state; and the second step, which was the main part of the tests, where the agitator was reduced to the lowest turbulent level of $0.57 \mathrm{~N} \mathrm{~m}^{-2}$ for a duration of $120 \mathrm{~min}$ as suggested by Mikes et al. (2004)); Verney et al. (2009). This 
is a significant period for flocculation to occur in natural water bodies (Le Hir et al. 2001). During the experiment, a series of images were recorded from the PIV system at different time steps to calculate the floc size distributions over the investigated period. To determine the effect of sediment concentration variation on flocs size and settling velocity, a set of laboratory experiments with suspended sediment concentration (SSC) of 100, 150 and $200 \mathrm{mg} \mathrm{l}^{-1}$ were conducted at two different salinities of $S=2.5$ and $S=20$ and at a low turbulent level of $\eta=0.57 \mathrm{~N} \mathrm{~m}^{-2}$. This value of turbulent level was chosen in this experiment because it was considered to represent optimum conditions for flocculation processes. In each test, the flocs were carefully extracted with a syringe, and then were slowly introduced into the settling column. The diameter of the syringe was sufficiently large to minimise floc breakage. This sampling protocol (syringe sampling) was successfully used and validated against in situ floc observations (Gratiot and Manning 2004; Manning et al. 2010c; Manning and Schoellhamer 2013). After the introduction of the sample into the water column, the flocs were allowed to settle by gravity over a distance of approximately $13 \mathrm{~cm}$ prior to switching the camera on to allow the damping out of any activity from the introduction method.

\subsection{Analysis}

The floc size distribution and settling velocity were obtained from the recording and processing of the floc images. The image processing comprised five steps: (1) selection of the flocs manually at the start and at the end of the sequence by opening images using image editor and paint program; (2) enhancing background (brightness and contrast); (3) removing any noise to make sure the flocs appear in all of the sequential images; (4) removing all flocs which are touching the image boundary and are not in focus and (5) calculating the features of flocs including: sectional area, location and circularity by using the "imageJ" software. As this method is interactive, there is very low risk of errors being made in the determination of the floc paths.

ImageJ was used to detect particles larger than $60 \mu \mathrm{m}$; below this limit, the pixel resolution of the floc measurement is not consistent and hence, the smallest microflocs are not accounted for in the description of the floc population during the experiment. Floc size was obtained using the contrast between the dark background and the white silhouettes of the floc. The surface equivalent diameter $d$ was calculated by converting particle area $(A)$ into equivalent circular diameter (Flory et al. 2004; Mikes et al. 2004; Verney et al. 2009) as

$d=\sqrt{\frac{4 A}{\pi}}$

\section{Results and discussion}

\subsection{Floc size distribution (FSD)}

The floc size distributions as a function of SSC $(100,150$ and 200) $\mathrm{mg} \mathrm{l}^{-1}$ at both salinity ranges of 2.5 and 20 are displayed in Fig. 3. Table 1 lists the eight bands of size distributions which were used in this study. Band 1 represents flocs with a size of less than $100 \mu \mathrm{m}$, whilst band 8 represents flocs with a size bigger than $700 \mu \mathrm{m}$ and bands 2 to 7 the size ranges in between. Floc size exhibits variability that increases with increasing SSC at both salinity ranges of 2.5 and 20 (Fig. 3). In this experiment, the only focus was on the influence of electrostatic force as the main factor in the formation of mud flocs. The floc size distribution for the data shows that particle sizes ranged from 75 to $800 \mu \mathrm{m}$, with the greatest numbers of flocs being $150-250 \mu \mathrm{m}$. The percentage of large flocs $(>700 \mu \mathrm{m})$ at $S 2.5$ decreases from 9 to $2 \%$ with increasing sediment concentrations from 100 to $200 \mathrm{mg} \mathrm{l}^{-1}$ as shown in Fig. 3a. This result is in good agreement with the results obtained by (Manning and Dyer 1999), who worked at the Tamar Estuary with in situ settling velocity (INSSEV). This decrease in the percentage of large flocs with increasing sediment concentration could be a result of the disruption caused by collisions (which increase in collision frequency as SSC increase), whilst aggregation at low sediment concentration and salinity of 20 is less than that at low sediment concentration and salinity of 2.5. The flocculation onset can occur at low salinity and low concentration. This is the best environment for floc size to reach the maximum size of more than $700 \mu \mathrm{m}$. This result is in good agreement with previous studies. Dobereiner and McManus (1983) found that coagulation increases at low salinities (1-2) based on data from the Tay Estuary. Gibbs and Konwar (1986) found that aggregate size in the Amazon Shelf depended on the salinity when salinity was less than 10. Wollast (1988) found that intense flocculation occurs as soon as salinity increases to about 1 and is complete when salinities have reached values above 2.5. Krone (1962); Migniot (1968); Lintern (2003); Allersma et al. (1967); Thill et al. (2001) show that the salinity variation affects flocculation up to a threshold with a further increase not having much effect. With increasing SSC at low salinity, the flocs are more likely to bump into each other more frequently which subsequently can cause flocs' breakdown. In this situation, the floc size is still larger than $700 \mu \mathrm{m}$, but the percentage of the large flocs is decreased by $7 \%$ (Fig. 3a). Figure $3 \mathrm{~b}$ indicates that at a high salinity of 20 , the particles do not exceed $500 \mu \mathrm{m}$ at SSC of $100 \mathrm{mg} \mathrm{l}^{-1}$. This stage might be transitory until a specific amount of sediment is attained, which gives particles a higher chance to bump into each other and reach sizes in excess of $700 \mu \mathrm{m}$ at SSC of $200 \mathrm{mg} \mathrm{l}^{-1}$ (see Fig. 3b).At $S$ of 20, the peak at SSC of 0.1 and $0.15 \mathrm{mg}^{-1}$ is almost the same, for floc sizes (100-200 $\mu \mathrm{m})$. The position of 
Fig. 3 Floc size distribution at various concentrations including the standard deviation between two runs: a $S=2.5 ; \mathbf{b} S=20$
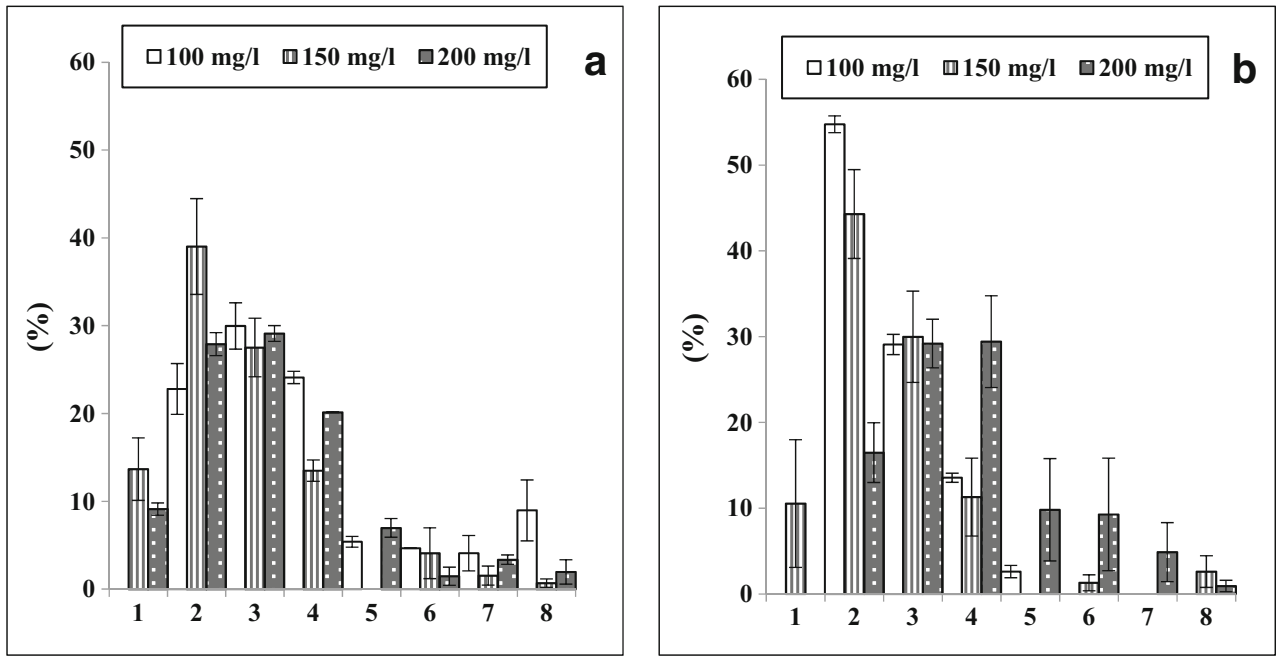

the peak moved with increasing SSC to $0.2 \mathrm{mg}^{-1}$ from smaller floc size towards larger floc size. At the same salinity range of (20), the maximum floc size increases with increasing SSC. A possible reason is that at high salinities of 20 , the probability of collision between particles is enhanced with increasing SSC. Consequently, the floc sizes increase with increasing SSC (Fig. 3b). At the same time, the floc density decreased (see Fig. 8) which contributed to the decreasing Ws with increasing SSC. Eisma et al. (1991) found that the increase in SSC will have an influence on reducing the turbulent level and is contributing to increasing the frequency of particle collisions and hence causing enhanced flocculation. Tsai et al. (1987) conclude that increased sediment concentration may enhance flocculation by increasing particle size due to increased frequency of particle collisions with increased SSC and reduction of inter-particle space.

Considering the result shown in Fig. 3a, b, a conceptual model was developed (Fig. 4). This model is based on the variation of the flocs' percentage related to their size depending on different salinity and suspended sediment concentrations. This conceptual model is characterised by two lines. The first line represents the floc size and its percentage at low sediment concentration and salinity, and at high sediment concentration and salinity. The second line presents the floc size and its percentage at high sediment concentration and lower salinity and at lower sediment concentration and higher salinity. It can be concluded that SSC and $S$ are both having an effect on the floc size. As SSC is increasing at low $S$, the influence of particle collisions can act as a floc break-up mechanism. At high $S$, the frequency of particle collision decreases with increasing SSC hence increasing the particle size.

\subsection{Settling velocity}

The relationship between the average floc size and settling velocity for a specific suspended sediment concentration (SSC) for both salinity ranges of 2.5 and 20 (Fig. 5a, b) illustrates that the settling velocity changes from 0.4 to $1.2 \mathrm{~mm} \mathrm{~s}^{-1}$ and from 0.2 to $1.1 \mathrm{~mm} \mathrm{~s}^{-1}$ for salinities of 2.5 and 20 , respectively. The settling velocity at salinity 2.5 displays a similar trend to experimental data presented by Burban et al. (1989), and the field data recently reported by Manning (2004b), where, at low shear stress the settling velocity was smaller at lowest SSC and increases with increasing SSC. This could be due to the floc density, which will be examined in the next section, the slow settling floc being of low density and low SSC, whereas, the fast settling values were a result of more dense flocs. Also, Pejrup and Mikkelsen (2010) found that the settling velocity increases with increasing SSC from 20 to $200 \mathrm{mg} \mathrm{l}^{-1}$ under fresh water conditions, based on data collected by Pejrup et al. (1997). This can be explained by the fact that at low salinity and high sediment concentration, the particles start bumping into each other which leads to a decrease of the flocs' surface area and the floc becomes denser. The collision frequency appeared to stimulating the increase of the settling velocity. Whereas, at high salinity of 20 , this situation is reversed and the faster settling velocity was found to occur at lower SSC. This could be the result of floc structure (Fig. 6). This figure shows the scanning electronic microscope (SEM) photographs of flocs at $S=20$ and turbulence of $0.57 \mathrm{~N} \mathrm{~m}^{-2}$ for SSC of 100 and $200 \mathrm{mg} \mathrm{l}^{-1}$. The flocs at sediment concentration of $200 \mathrm{mg} \mathrm{l}^{-1}$ become unstable and more fragile (less dense) as they grow, and the flocs at low
Table 1 The definition of floc size band

\begin{tabular}{lllllllll}
\hline Size band & 1 & 2 & 3 & 4 & 5 & 6 & 7 & 8 \\
\hline Floc size $(\mu \mathrm{m})$ & $<100$ & $100-200$ & $200-300$ & $300-400$ & $400-500$ & $500-600$ & $600-700$ & $>700$ \\
\hline
\end{tabular}




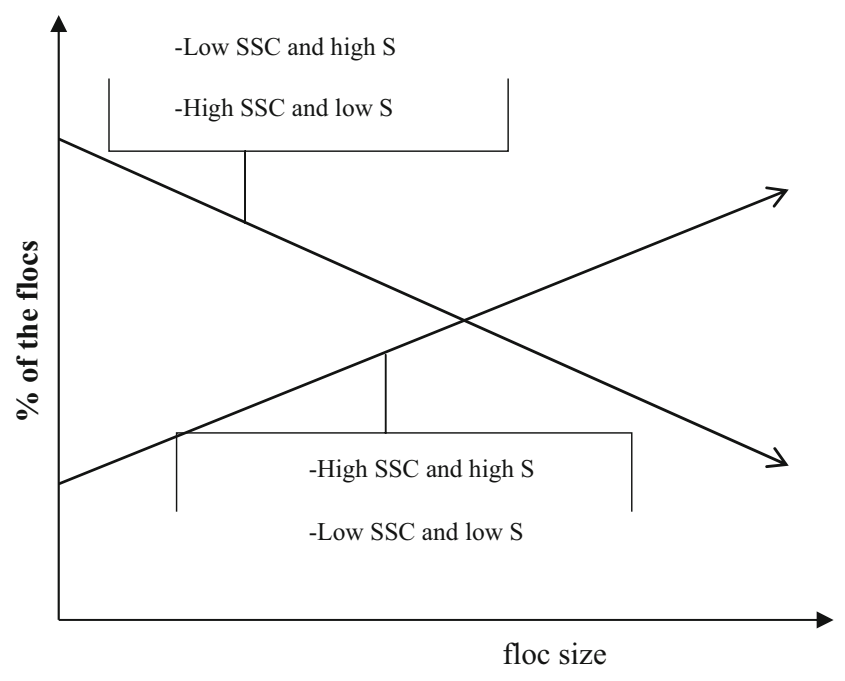

Fig. 4 Schematic representation of the salinity and sediment concentration influence on the percentage and the maximum size of the floc

SSC of $100 \mathrm{mg}^{-1}$ are more dense. Therefore, it was expected that the settling velocity would decrease with increasing sediment concentration for this range of salinity (20). The settling velocity at the concentration of $200 \mathrm{mg} \mathrm{l}^{-1}$ and both salinity ranges of 2 and 20 is interesting (Fig. $5 \mathrm{a}, \mathrm{b}$ ). The sediment settling velocity at $S 20$ was $0.37 \mathrm{~mm} \mathrm{~s}^{-1}$ which was $54 \%$ or $0.43 \mathrm{~mm} \mathrm{~s}^{-1}$ slower than the settling velocity of flocs generated at low salinity (2.5). This could be the result of floc structure and density. The decrease in the settling velocity with increasing salinity is perhaps due to the formation of flocs with lower densities in the high salinity range (Johansen 1998). The aim of Fig. 5a, b was to develop a settling velocity equation as a function of SSC and floc size (d) for two salinity ranges of 2.5 and 20 . The SSC was chosen in this study as the important variable which governs the collision rate and subsequent degree of flocculation of particles in estuarine water. The formation of aggregate at high and low salinities was chosen to simulate the natural processes of the cohesive particles in the estuary as they are passing through freshwater and into high saline waters. Floc size was chosen as an important variable based on previous studies in different estuaries. Dyer et al. (1996) concluded that a single value of mean or median settling velocity did not adequately represent the floc size distribution. They suggested that an accurate representation of floc settling velocity can be derived by splitting the floc distribution into two or more components, each with their own mean settling velocity. Manning (2001) proposed that an accurate representation of floc population can be carried out by split floc distribution into two components, i.e. microflocs and macroflocs fractions, by employing a floc diameter of $160 \mu \mathrm{m}$ as the limited size between the microfloc and macrofloc fractions. In this study, the floc distribution was split into four components, each with their own mean floc size and settling velocity Fig. 5. The Minitab 17 statistical package was used to model the experimental data and perform a multiple linear regression analysis with statistical confidence level of $95 \%$. This model accounts for the variation in settling velocity $\left(\mathrm{mm} \mathrm{s}^{-1}\right)$ of mud flocs as a function of $\mathrm{d}$ (in $\mu \mathrm{m}$ ) and SSC $\left(\mathrm{g}^{-1}\right)$ for salinities of 2.5 and 20 and shear stress of $0.57 \mathrm{~N} \mathrm{~m}^{-2}$. The regression equations between aggregate size and concentration for $S=2.5$ and $S=20$, respectively can be expressed as:

$w_{s}=0.45-0.93 \mathrm{SSC}+0.0006 d+0.0097 \mathrm{SSC} d$

$w_{s}=0.36-0.84 \mathrm{SSC}+0.0037 d+0.0148 \mathrm{SSC} d$

The regression eqs. (2) and (3) were represented by the solid lines in Fig. 5 with the individual points being the data upon which the regression analysis is based. The small derivation between the experimental data and those obtained by the multiple regressions is shown by the $R^{2}$ values of 0.95 and 0.93 for formulae (2) and (3), respectively. This is a general
Fig. 5 Settling velocity for various concentrations (different symbols) against floc size at (a) $S=2.5$ and (b) $S=20$. The range shows the standard deviation between two runs
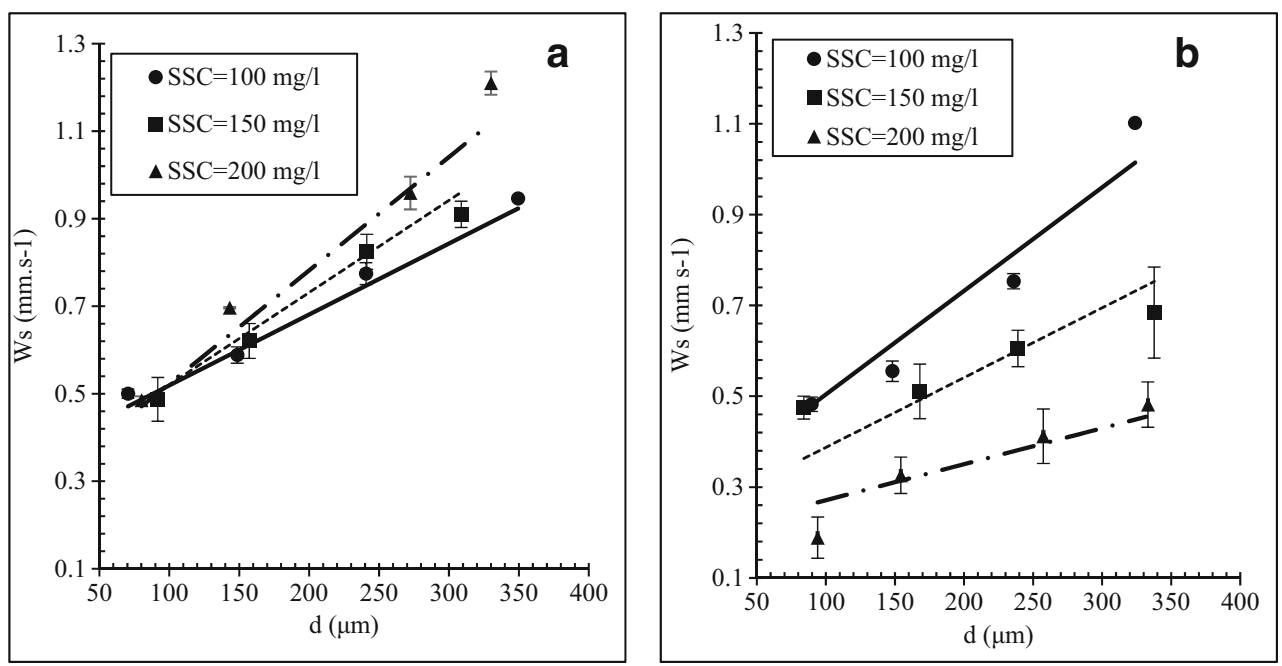
Fig. 6 A selection of SEM photographs of flocs at $S=20$, different SSC, $a=100$ and $b=200 \mathrm{mg}^{-1}$
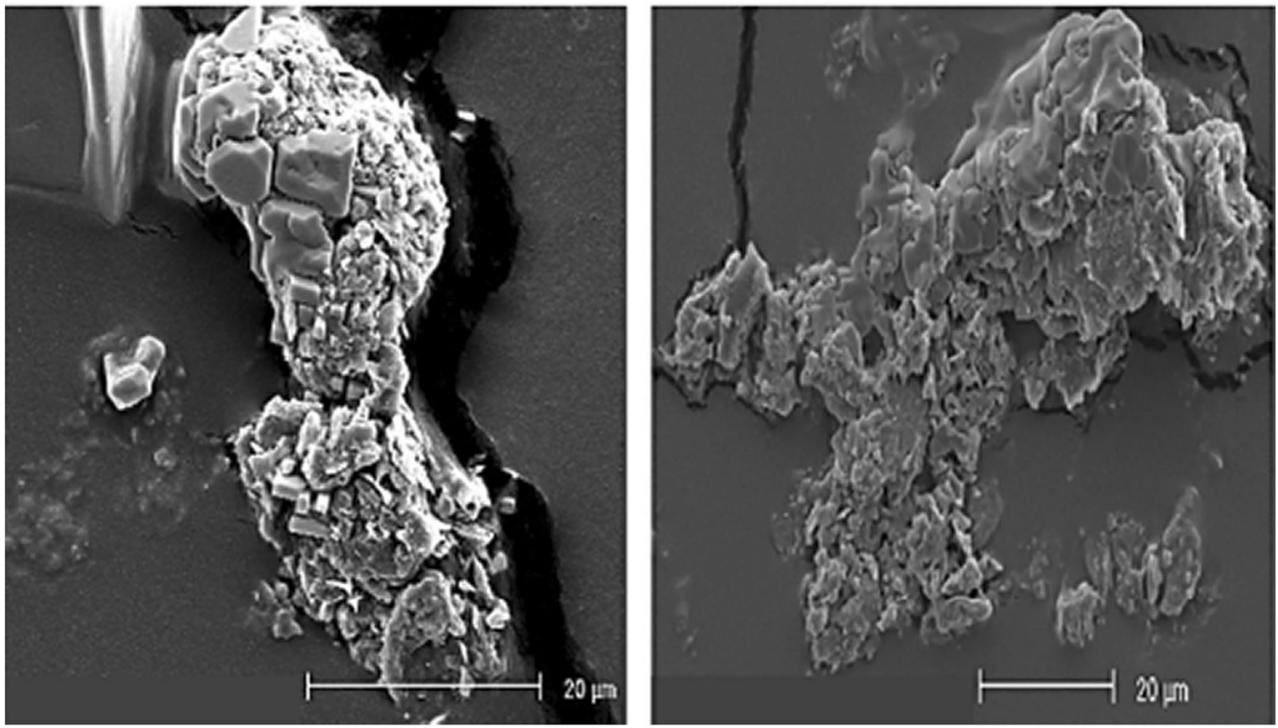

improvement into the numerical model where the settling velocity is only considered to be a function of turbulence and salinity. These results need to be compared with in situ measurements and numerical model outputs before they can confidently be used in predictive models.

\subsection{Floc structure and density}

The floc structures are shown in Fig. 6 with the SEM photographs at two different sediment concentrations of 100 and $200 \mathrm{mg} \mathrm{l}^{-1}$. As the floc structure cannot be measured directly using the PIV camera, the fractal dimension of flocs (nf) is determined theoretically using the Winterwerp model (Winterwerp 1999). This model was developed based on field and laboratory data. The settling velocity as a function of floc size was plotted with the Winterwerp model and compared with those in previous published studies, as shown in Fig. 7. The magnitude of the Ws values observed during the present study is higher than those observed in the laboratory by Verney et al. (2009), which could be a result of the method used to analyse the data. In this study, each floc size was plotted with its settling velocity (Fig. 7), whilst Verney et al. (2009) utilise the mean floc size to compute the floc settling velocity. We observed that Ws of aggregates at $S$ of 2.5 are higher than at $S$ of 20 . The trend of settling velocities at both salinity ranges is similar to the findings of an experimental study conducted by Lick et al. (1993), although the gradient in the trend found in our experiments is lower. Our experimental results at $S$ of 2.5 are similar to those of Manning and Dyer (1999) in the region of $d(70-140) \mu \mathrm{m}$ and slightly different in the region of $d(140-200) \mu \mathrm{m}$. It is clear that the laboratory data of the present study matches well with the Winterwerp model. The overall trend of the experimental data points seems slightly steeper than his model for the fractal dimension (nf) of 2 .

However, when the individual data set are studied, the slope agrees better with nf between 2 and 2.3 for salinity 2.5, and nf between 1.7 and 2 for salinity 20 . This result indicated that the floc size becomes more irregular in shape with increasing salinity ranges. It is important to work with $\mathrm{nf}$ value as the density is more realistic than Stoke's law. As in Stoke's law, the density calculated is based on the assumption that the flocs have a spherical diameter. By knowing nf value from this chart, it will be easy to calculate the floc density from the theoretical equation. The effective density also known as the excess density $\left(\rho_{e}\right)$, which is defined as the difference between the floc bulk density $\left(\rho_{f}\right)$ and water density $\left(\rho_{w}\right)$, was obtained by applying Stoke's law eq. (4). This equation has been widely used by Dyer and Manning (1999); Mantovanelli and Ridd (2008).

$\rho_{e}=\rho_{f}-\rho_{w}=\left(\rho_{s}-\rho_{w}\right)\left(\frac{d}{d_{i}}\right)^{n f-3}$

Where $\rho_{f}$ is the floc density, $\rho_{w}$ is the water density, $\rho_{s}$ is the mud density, $d$ is the equivalent spherical diameter, $d_{i}$ is the diameter of the primary particle and $n_{f}$ is the fractal dimension.

In eq. (4), a different fractal dimension is used to calculate $\rho_{e}$, in order to adequately represent the variation of effective density under varying SSC and $S$. Figure 8 presents the effective density as a function of floc size for all the flocs data. The floc effective densities ranged from 30 to $350 \mathrm{~kg} \mathrm{~m}^{-3}$. The effective density decreases with increasing diameter. This relationship has been observed by different authors e.g. (Krone 1962; Winterwerp 1999; Winterwerp et al. 2006).The aggregate formation at $S$ of 2.5 demonstrates an increase of effective density with a constant floc size as SSC increases. This 
Fig. 7 Relation between settling velocity and floc size, $\mathrm{nf}$ defined as the fractal dimension

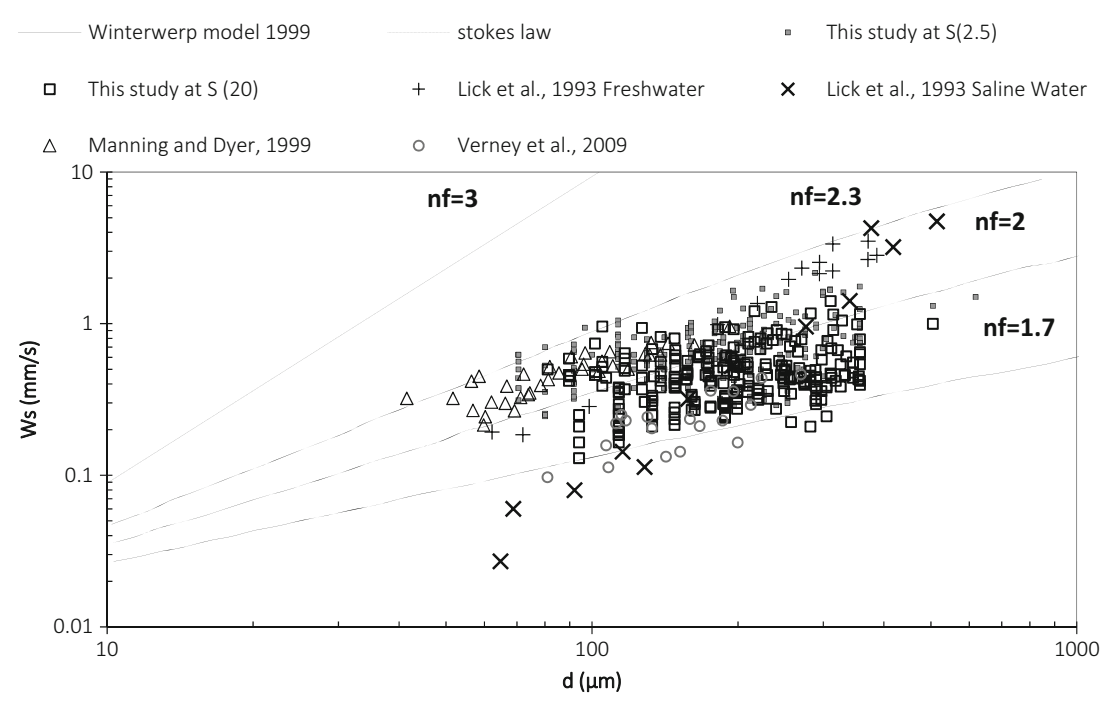

observation has been reported previously by Gratiot and Manning (2004). In contrast, at high $S$ of 20 , the $\rho_{e}$ decreases with a constant floc size as SSC increases. This can be explained by a decrease in the floc density meaning an increase in the porosity, which leads to an increase in the water content that forces the density of the floc towards the density of the water and tends to reduce the settling velocity (Droppo et al. 1997). These results need to be compared with in situ measurements and numerical model outputs before they can be confidently used in predictive models. This is planning to be achieved in the future work by improving the instrumentation and using a strong enough light to detect smaller particles and as well as to be able to use higher sediment concentrations in the experiment which will better mimic the field sediment concentration in the Severn Estuary.

\section{Conclusions}

The potential impacts of the hydrodynamic parameters (i.e. salinity and suspended sediment concentration) on the floc size and settling velocity were assessed in this study using suspended sediment samples from the Severn Estuary in controlled laboratory experiments. The percentage of large flocs increased with increasing sediment concentration at high salinity. However, the situation reversed at lower salinity where the percentage of large flocs decreased by nearly $7 \%$ with increasing sediment concentrations from 100 to $200 \mathrm{mg} \mathrm{l}^{-1}$.

The results highlight that the floc size and hence settling velocity is controlled by an interaction between salinity and SSC. The faster settling velocity occurred at the higher concentrations when salinity was low (2.5). At higher salinity (20)
Fig. 8 The relationship of the flocs size to the effective density

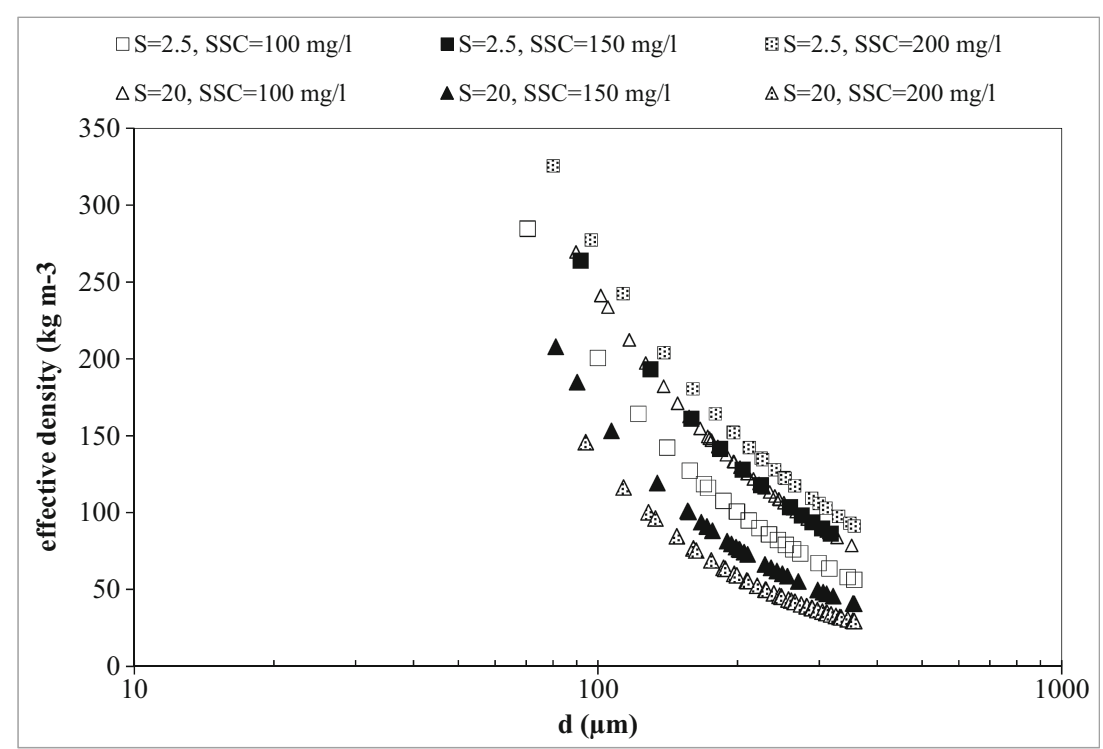


alongside increasing SSC, the situation was reversed, i.e. the lower the sediment concentration, the faster the settling velocity. The experimental data compared favourably with the field and laboratory data from the literature.

Representation of these processes in hydrodynamic estuarine models will contribute to a better understanding to help best manage estuarine and coastal waters under future stresses such as climate change. In future work, we plan to apply and refine a numerical model to include the settling velocity function taking into account salinity and turbulence levels, so that flocculation mechanisms (floc size and settling velocity) can be considered more realistically for the field scale, and for the direct impact on morphological and water quality processes. However, this is beyond the scope of the work presented here. Also, future work will include a comparison of the PIV finds against measurements using established floc settling velocity and floc size techniques.

Acknowledgments The Libyan government is gratefully acknowledged for its financial support through a PhD studentship for one of the authors.

Open Access This article is distributed under the terms of the Creative Commons Attribution 4.0 International License (http:// creativecommons.org/licenses/by/4.0/), which permits unrestricted use, distribution, and reproduction in any medium, provided you give appropriate credit to the original author(s) and the source, provide a link to the Creative Commons license, and indicate if changes were made.

\section{References}

Allersma E, Hoekstra A, Bijker E (1967) Transport patterns in the Chao Phya estuary. Delft Hydraulics Laboratory, Delft, Delft

Burban P-Y, Lick W, Lick J (1989) The flocculation of fine-grained sediments in estuarine waters. J Geophys Res: Oceans 94:8323-8330

Cheviet C, Violeau D, Guesmia M (2002) Numerical simulation of cohesive sediment transport in the Loire estuary with a three-dimensional model including new parameterisations. Proc Mar Sci 5:529-543

Dobereiner C, McManus J (1983) Turbidity maximum migration and harbour siltation in the Tay estuary. Can J Fish Aquat Sci 40:117129

Droppo IG, Leppard GG, Flannigan DT, Liss SN (1997) The freshwater floc: a functional relationship of water and organic and inorganic floc constituents affecting suspended sediment properties. Wat Air Soil Pollut 99:43-53

Dyer KR, Manning AJ (1999) Observation of the size, settling velocity and effective density of flocs, and their fractal dimensions. J Sea Res 41:87-95

Dyer KR, Cornelisse J, Dearnaley MP, Fennessy MJ, Jones SE, Kappenberg J, McCave IN, Pejrup M, Puls W, Van Leussen W, Wolfstein K (1996) A comparison of in situ techniques for estuarine floc settling velocity measurements. J Sea Res 36:15-29

Eisma D (1986) Flocculation and de-flocculation of suspended matter in estuaries. Neth J Sea Res 20:183-199

Eisma D, Bernard P, Cadée GC, Ittekkot V, Kalf J, Laane R, Martin JM, Mook WG, van Put A, Schuhmacher T (1991) Suspended-matter particle size in some west-European estuaries; Part II: a review on floc formation and break-up. Neth J Sea Res 28:215-220
Fennessy MJ, Dyer KR, Huntley DA (1994) Inssev: an instrument to measure the size and settling velocity of flocs in situ. Mar Geol 117:107-117

Flory EN, Hill PS, Milligan TG, Grant J (2004) The relationship between floc area and backscatter during a spring phytoplankton bloom. Deep Sea Res Part I: Oceanogr Res Pap 51:213-223

Gao G, Falconer R, Lin B (2011) Numerical modelling sediment-bacteria interaction processes in the Severn Estuary. J Water Resour Prot 3: 22-31

Gibbs RJ, Konwar L (1986) Coagulation and settling of Amazon River suspended sediment. Cont Shelf Res 6:127-149

Gratiot N, Manning AJ (2004) An experimental investigation of floc characteristics in a diffusive turbulent flow. J Coast Res SI 41: $105-113$

Hjulström F (1935) Studies of the morphological activity of rivers as illustrated by the River Fyris. Dissertation, University of Uppsala

Johansen C (1998) Dynamics of cohesive sediment. Dissertation, University of Aalborg

Jonas PJC, Millward GE (2010) Metals and nutrients in the Severn Estuary and Bristol Channel: contemporary inputs and distributions. Mar Pollut Bull 61:52-67

Kadiri MB-E, Zhou J, Falconer R (2014) Water quality impacts of a tidal barrage in the Severn Estuary, UK. Paper presented at the 10th ISE 2014, Trondheim, Norway, June 23-27

Kirby R (2010) Distribution, transport and exchanges of fine sediment, with tidal power implications: Severn Estuary, UK. Mar Pollut Bull 61:21-36

Kirby R, Wurpts R, Greiser N (2008) Chapter 1 emerging concepts for managing fine cohesive sediment. Proc Mar Sci 9:1-15

Krone RB (1962) Flume studies of the transport of sediment in estuarial shoaling processes. Hydraulic Engineering Laboratory and Sanitary Engineering Research Laboratory, University of California, Berkeley

Lafite R (2001) Impact de la dynamique tidale sur le transfert de sédiments fins. Dissertation, Université de Rouen

Le Hir P, Ficht A, Silva Jacinto R, Lesueur P, Dupont JP, Lafite R, Brenon I, Thouvenin B, Cugier P (2001) Fine sediment transport and accumulations at the mouth of the Seine estuary (France). Estuar 24:950963

Lick W, Huang H, Jepsen R (1993) Flocculation of fine-grained sediments due to differential settling. J Geophys Res: Oceans 98: $10279-10288$

Lintern DG (2003) Influences of flocculation on bed properties for finegrained cohesive sediment. Dissertation, Oxford University

Maggi F (2005) Flocculation dynamics of cohesive sediment. Dissertation, University of Technology

Manning AJ (2001) Study of the effect of turbulence on the properties of flocculated mud. Dissertation, University of Plymouth

Manning AJ (2004a) Observations of the properties of flocculated cohesive sediment in three western European estuaries. J Coast Res SPEC ISS 41:70-81

Manning AJ (2004b) The observed effects of turbulence on estuarine flocculation. J Coast Res SPEC ISS 41:90-104

Manning AJ, Dyer KR (1999) A laboratory examination of floc characteristics with regard to turbulent shearing. Mar Geol 160:147-170

Manning AJ, Dyer KR (2007) Mass settling flux of fine sediments in northern European estuaries: measurements and predictions. Mar Geol 245:107-122

Manning AJ, Schoellhamer DH (2013) Factors controlling floc settling velocity along a longitudinal estuarine transect. Mar Geol 345:266280

Manning AJ, Dyer KR, Lafite R, Mikes D (2004) Flocculation measured by video based instruments in the Gironde Estuary during the European Commission SWAMIEE project. J Coast Res SPEC ISS 41:58-69 
Manning AJ, Baugh JV, Spearman JR, Whitehouse RJS (2010a) Flocculation settling characteristics of mud: sand mixtures. Ocean Dyn 60:237-253

Manning AJ, Langston WJ, Jonas PJC (2010b) A review of sediment dynamics in the Severn Estuary: influence of flocculation. Mar Pollut Bull 61:37-51

Manning AJ, Schoellhamer DH, Mehta AJ, Nover D, Schladow SG (2010c) Video measurements of flocculated sediment in lakes and estuaries in the USA. Paper presented at the Proceedings of the Joint Federal Interagency Conference on Sedimentation and HyVdrologic Modeling, Riviera Hotel, Las Vegas, Nevada, USA, 27th June-1st July 2010

Manning AJ, Baugh JV, Spearman JR, Pidduck EL, Whitehouse RJS (2011) The settling dynamics of flocculating mud-sand mixtures: part 1-empirical algorithm development. Ocean Dyn 61:311-350

Manning AJ, Spearman JR, Whitehouse RJS, Pidduck EL, Baugh JV, Spencer KL (2013) Flocculation dynamics of mud: sand mixed suspensions. In: Manning AJ (ed) Sediment transport processes and their modelling applications, 1st edn. InTech, Croatia, pp 116-164

Mantovanelli A, Ridd PV (2008) Sedvel: an underwater balance for measuring in situ settling velocities and suspended cohesive sediment concentrations. J Sea Res 60:235-245

McLaren P, Collins MB, Gao S, Powys RIL (1993) Sediment dynamics of the Severn Estuary and inner Bristol Channel. J Geol Soc Lond 150:589-603

Mehta AJ (2014) An introduction to hydraulics of fine sediment transport. World Scientific, UK

Migniot C (1968) Etude des propriétés physiques de différents sédiments très fins et de leur comportement sous des actions hydrodynamiques. La Houille Blanche 7:591-620

Mikes D, Verney R, Lafite R, Belorgey M (2004) Controlling factors in estuarine flocculation processes: experimental results with material from the Seine Estuary, Northwestern France. J Coast Res SPEC ISS 41:82-89

Pejrup M, Mikkelsen OA (2010) Factors controlling the field settling velocity of cohesive sediment in estuaries. Estuar Coast Shelf Sci $87: 177-185$
Pejrup M, Larsen M, Edelvang K (1997) A fine-grained sediment budget for the Sylt-Rømø tidal basin. Helgoländer Meeresuntersuchungen 51:253-268

Serra T, Casamitjana X (1998) Structure of the aggregates during the process of aggregation and breakup under a shear flow. J Collo Inter Sci 206:505-511

Serra T, Colomer J, Casamitjana X (1997) Aggregation and breakup of particles in a shear flow. J Collo Inter Sci 187:466-473

Soulsby RL, Manning AJ, Spearman J, Whitehouse RJS (2013) Settling velocity and mass settling flux of flocculated estuarine sediments. Mar Geol 339:1-12

Spearman JR, Manning AJ, Whitehouse RJS (2011) The settling dynamics of flocculating mud and sand mixtures: part 2-numerical modelling. Ocean Dyn 61:351-370

Thill S, Moustier S, Garnier JM, Estournel C, Naudin JJ, Bottero JY (2001) Evolution of particle size and concentration in the Rhône river mixing zone : influence of salt flocculation. Cont Shelf Res 21:2127-2140

Tsai C-H, Iacobellis S, Lick W (1987) Flocculation of fine-grained lake sediments due to a uniform shear stress. J Grt Lakes Res 13:135-146

Verney R, Lafite R, Brun-Cottan JC (2009) Flocculation potential of estuarine particles: the importance of environmental factors and of the spatial and seasonal variability of suspended particulate matter. Estuar Coast 32:678-693

Whitehouse R, Soulsby RL, Roberts W, Mitchener H (2000) Dynamics of estuarine muds. Thomas Telford, London. https://doi.org/10.1680/ doem. 28647

Winterwerp JC (1999) On the dynamics of high-concentrated mud suspension. $\mathrm{PhD}$, University of Technology

Winterwerp JC, Manning AJ, Martens C, de Mulder T, Vanlede J (2006) A heuristic formula for turbulence-induced flocculation of cohesive sediment. Estuar Coast Shelf Sci 68:195-207

Wollast R (1988) The Scheldt Estuary. In: Salomons W, Bayne BL, Duursma EK, Förstner U (eds) Pollution of the north sea: an assessment. Springer, Berlin, pp 183-193. https://doi.org/10.1007/978-3642-73709-1_11 